\title{
Stigma and disclosure: Implications for coming out of the closet
}

\author{
PATRICK W. CORRIGAN ${ }^{1} \&$ ALICIA K. MATTHEWS ${ }^{2}$ \\ ${ }^{I}$ Center for Psychiatric Rehabilitation \& ${ }^{2}$ Department of Psychiatry, \\ University of Chicago, Chicago, Illinois, USA
}

\begin{abstract}
Background: There are costs and benefits for people with psychiatric disorders to decide to disclose publicly these disorders.

Aims: The gay and lesbian community has struggled with the same tension and their discoveries about coming out may prove useful for the disclosure concerns of persons with mental illness.

Methods: Lessons learned about coming out by the gay and lesbian community include a variety of models that map the stages for successfully coming out; e.g., identity confusion, comparison, identify acceptance, immersion, and identity synthesis. Navigating these stages requires consideration of the costs and benefits of disclosure; we review some of these including social avoidance and disapproval as key costs and improved psychological wellbeing and interpersonal relations as benefits.

Conclusions: The paper ends with a review of levels of disclosure for people who opt to come out.

Declaration of interest: This paper was made possible in part by MH62198-01 from the National Institute of Mental Health.

Keywords: mental illness, stigma, coming out, gays
\end{abstract}

\section{Dealing with the stigma of mental illness by coming out of the closet}

Harvey Milk, the first openly gay supervisor of San Francisco, once said, 'I would like to see every gay lawyer, every gay architect come out, stand up and let the world know. That would do more to end prejudice overnight than anybody could imagine.' (cited in Herek, 1996, p. 213).
Advocates and researchers agree that one way to challenge the stigma of mental illness is through contact. Members of the general public are more likely to diminish prejudicial attitudes and discriminating behaviors when they have contact with people with mental illness. This parallels a basic finding about change in racial prejudice; namely, the white majority decreased prejudice and discrimination when they had contact

Address for Correspondence: Patrick Corrigan, 7230 Arbor Drive, Tinley Park, IL 60477, USA; Tel: 708 6144770; Fax 708 614-4780; E-mail: p-corrigan@uchicago.edu; www.stimgaresearch.org 
with people of color (Johnson \& Johnson, 2000; Jones et al., 2000). The experience of mental illness stigma differs from racism in that the stigma of mental illness may be hidden while the signs that yield racial discrimination are largely manifest. Hence, the experience of mental illness is like many other groups in which members may hide their association, groups including minority subsets of sexual orientation, educational attainment, and social status (Corrigan \& Lundin, 2001).

Despite the ability of many individuals to conceal their sexual orientation, the gay and lesbian community has discovered that their community benefits when individuals choose to disclose their sexual orientation. In this article, we argue that the community of people with mental illness may similarly benefit from disclosing their illness to the public at large. We assert that what is known about 'coming out' in terms of sexual orientation may provide hypotheses and methods that might guide future research in this area as it relates to mental illness. However, it should be noted that in comparing the experiences of sexual minorities to those with mental illness, we are in no way implying that any aspects of gay, lesbian, bisexual, or transgender orientations represent a psychiatric disorder. A second, equally important point also needs to be made. In stating that homosexuality is not a psychiatric disorder, we have reinforced the notion that being mentally ill is in someway morally wrong. Assertions like these are equally unjust and need to be corrected.

\section{How contact changes stigma}

Before we juxtapose the experiences of sexual minorities to those with mental illness, we will briefly review the literature on the relationship between social contact and stigma. Here we review the three ways of changing public stigmaprotest, education, and contact-and the body of evidence on the strengths and weaknesses of each. Briefly, protest strategies highlight the injustice of specific stigmas and lead to a moral appeal for people to stop thinking that way. Education strategies have largely focused on replacing the emotionally charged myths of mental illness (e.g., people with mental illness are dangerous!) with facts that counter the myths (e.g., on average, people with mental illness are no more dangerous than the rest of the population). Although research suggests that these interventions might lead to mild change in attitudes (Holmes et al., 1999; Keane, 1991; Morrison, 1980; Penn et al., 1994) and limited change in behavior (Corrigan et al., in press), research has shown contact to yield the best changes in stereotypes, prejudice, and discrimination.

Contact effects are understood in terms of familiarity. Research shows that members of the general public who are more familiar with individuals labeled mentally ill are less likely to endorse prejudicial attitudes (Holmes et al., 1999; Link \& Cullen, 1986; Penn et al., 1994, 1999). Moreover, members of the general public who interact with a person with mental illness as part of an anti-stigma program show significant changes in their attitudes (Corrigan et al., 2001). A subsequent study has shown that attitude change that results from contact maintains over time and is related to a change in behavior (Corrigan et al., 2003). In a similar vein, Herek (1986) and Herek \& Capitanio (1996) observed that contact between homosexuals and heterosexuals 
diminished stigmatizing attitudes among heterosexuals. Hence, he concluded that coming out (one way to facilitate contact) has significant value for diminishing the stigma experienced by gay men and lesbians. Given that many gays and lesbians have benefited from decisions regarding coming out, it is not unreasonable, given the similarities, that people with mental illness can benefit from these lessons. Some of these lessons, and their relevance for people with mental illness, are reviewed here.

\section{Parallel societal experiences}

In this paper, we seek to better understand ways which people might manage the stigma of mental illness by comparing their experiences to gays, lesbians, and bisexuals. For this enterprise to be fruitful, we must first demonstrate that the comparison is valid. First, the mark that signals the stigma of homosexuality and of mental illness is not readily transparent. Goffman (1963) distinguished stigmatized groups like these from groups whose stigmatizing mark is readily observed (e.g., skin color). This notion may seem contrary to naïve psychological notions that gays and people with mental illness are easily recognizable. Members of the general public may list several cues that are thought to be characteristic of each group but in fact lead to mistaken identification. For example, labeling effeminate men as gay will lead to false positives (Brookey, 2000). Similarly, tagging eccentric or unkempt people as mentally ill leads to erroneous identifications (Corrigan, 2000).

Yet another commonality lies in the vagaries of categorical distinctiveness between the stigmatized group and the majority. On one hand, naïve psychological notions might suggest that homosexuality (and mental illness) distinguishes a unique category from the rest of the population (straights or non-mentally ill). They are frequently described as binary groups (Cover, 2000): a person is either straight or gay, mentally ill or sane. This kind of duality is false and accentuates the "we versus they' qualities that augment stigma (Link \& Phelan, 2001). Similarly, the boundary between mental illness and 'normal' is gray. First, epidemiological research suggests that the prevalence rate of major mental illnesses is as high as $20 \%$ thereby debunking the idea that mental illness is a rare occurrence (Narrow et al., 2002). Second, and more germane to the point here, many of the characteristic symptoms of mental illness are quite common at subclinical levels. Hence, like gay versus straight, a clear distinction between the sane and mentally ill is not borne out by the data.

Another commonality is the way in which experiences with stigma emerge in the two communities. This similarity can be understood by contrasting it to the experiences of those whose stigma is readily manifest from birth. For example, members of stigmatized ethnic minority groups are born into families and communities who typically bear the same marks, are aware of potential prejudice that results from the stigma, and provide guidance for how to respond to prejudice. Conversely, the life experiences that result in someone calling themselves gay or mentally ill typically occur in adolescence and young adulthood rather than at birth (Fisher \& Akman, 2002; Weiser et al., 2001). Consequently, sexual minorities and individuals with mental illness often undergo a developmental process 
that is different from their primary care providers and larger support systems. At the worst, family members and others ostracize the person who is struggling with either their gay or mentally ill identity (Savin-Williams, 2001). More commonly, parents and other mentors are unable to provide any clarity to their experiences.

Finally, both groups have been stigmatized because of similar, society-wide misperceptions. In earlier times, homosexuality and mental illness were both viewed in moral terms. Homosexuality represented a volitional decision to opt for a sinful lifestyle (Zachary, 2001). Mental illness embodied the demonpossessed individual who did not have sufficient moral backbone to hold off Lucifer (Kinzie, 2000). The nineteenth and twentieth centuries replaced the religious models with views that medicalized the conditions (Duberman, 1993; Foucault, 1980). The DSM-I defined homosexuality as a sexual deviation involving pathological behavior (American Psychiatric Association, 1952). DSM-II cut the category of sociopathic personality disturbances from the definition but continued to list homosexuality among deviant sexual practices (American Psychiatric Association, 1968). At the same time, most of what has been considered to be major mental illnesses (e.g., schizophrenia) have been defined as medical conditions (American Psychiatric Association, 1952, 1968, 1980). Note that homosexuality per se was removed as a psychiatric disorder from DSM-III (American Psychiatric Association, 1980) while mental illnesses obviously are the only focus of the diagnostic manual.

Implicit in the medicalizing of a phenomenon is the idea that it can be corrected through treatment. During much of the twentieth century, some mental health professionals believed homosexuality could be cured through intensive psychotherapy. Most social scientists and health care professional now recognize gays and lesbians as an alternative sexual orientation that is not an appropriate target of psychotherapy (Davies \& Neal, 2000). In some ways, parallels between the experiences of sexual minorities and the mentally ill diminish here. As noted above, mental illnesses have appropriately continued to be construed by the psychiatric community as medical conditions (American Psychiatric Association, 1987, 1994, 2000) while sexual orientation has not. The parallel between homosexuality and mental illness also diminishes when considering issues related to treatment. Although there are several mental health survivor groups that question the legitimacy of psychiatric treatment (Crossley, 1998), empirical research generally suggests that most people with mental illness are better able to accomplish life goals when receiving evidence-based pharmacotherapy and psychosocial services (Drake et al., 2001). Hence, unlike gays and lesbians, treatment may play an important role in the lives of many people with major mental disorders.

One other difference seems to emerge between sexual minorities and people with mental illness; embracing their identity. Most advocates and researchers agree that essential to the psychological well-being of gays, lesbians, and bisexuals is embracing their sexual orientation (Besner \& Spungin, 1995). At first appearances, the parallel does not seem to hold for people with mental illness. Rare would be the suggestion that a person needs to embrace their illness. Instead, it seems from the perspective of 
patient and doctor that the number one goal of membership in the mental illness group is to get out of it. Some clinicians and advocates assert, however, that a necessary part of recovery is identifying the role that one's experience with mental illness plays in defining the self (Fisher, 1994; Mosher \& Burti, 1992). Despite the reasonableness of this perspective, a review of the literature yielded no empirical studies on identity development among people with mental illness.

Despite the paucity of information about identity development among people with mental illness, there is an important literature on disease insight that may be relevant here (Amador \& Kronengold, 1998; McEvoy, 1998). However, the professional literature mostly views mental illness as a pathogen that interferes with identity development. This difference in viewpoints is ripe for conceptual development and empirical testing in two ways. First, does mental illness as an experience have significance for identity development in ways other than disruption? If yes, then second, what models might explain identity and identity development in people with mental illness? Some models of identity development relevant to gays and lesbians are reviewed in the next section as possible candidates.

\section{Lessons learned on coming out}

Researchers studying sexual minorities have developed a series of models that represent identity development in this population (McCarn \& Fassinger, 1996; Rosario et al., 2001; Vincke, 1999). One model with a fair amount of empirical support has described the process of integrating a lesbian and gay identity into the self-concept by dividing it into five stages (Brady \& Busse, 1994; Cass, 1979, 1984; Sophie, 1985). We extrapolate these stages here to issues related to identity development for people with mental illness.

During the first two stages-identity confusion and comparison-people begin to question their sanity. They are aware of their psychiatric symptoms and feel alienated from the seemingly 'normal' population. Slowly, people in this situation learn to tolerate this new identity and seek out others with mental illness. At the identity acceptance stage of identity development, people decide to disclose to trusted others. Concern and fear about one's mental illness may be replaced by acceptance or pride. Some people become immersed in the culture of consumer, survivor, and ex-patient groups (Frese \& Davis, 1997; Trainor et al., 1997). Moreover, there is a rejection of values in the dominant culture; one way this shows is the anti-psychiatry movement (Crossley, 1998). Finally, the relative extremism of identity pride observed during the immersion stage is replaced by identity synthesis such that the person's identity as mentally ill becomes only one aspect of their identity.

Cass' (1979) model of identity integration assumes statements like 'I am gay and proud of it!' are an essential element of developing a healthy self-concept. It is still unclear whether a parallel exists in mental illness: 'I am mentally ill and proud of it.' Is this a necessary part of the self that needs to be recognized and included into an integrated view of one's self? An alternative way to view statements like 'I am mentally ill and proud of it!' may be as a necessary political assertion. Namely, because people with mental illness are discriminated by the majority, they may need to identify their 
similarities as a stigmatized group to obtain greater social power. In this case, an identity model like Cross' (1971) may be illustrative of the development process. Several studies have empirically validated aspects of his paradigm (Hall et al., 1972; Mio \& Iwamasa, 1993; Parham, 1989; Ponteretto \& Sabnani, 1989; Ridley et al., 1994). Cross' model seeks to map identity development in African Americans as they move from a 'Negro' identity, which included some of the majority groups stereotypes, to a 'Black' identity which represents views that emerge from the African American community. Once again, we explain the model in terms of how it might apply to people with mental illness.

During the pre-encounter stage, people with mental illness are unaware of their political plight and of the way that assumptions by the seemingly 'normal' majority influence attitudes about them. The subsequent encounter stage brings into awareness these subtle assumptions in two ways. First, people experiencing early signs of significant psychiatric symptoms are challenged by their view of normalcy. Second, people struggling with psychiatric symptoms encounter advocates who are out of the closet and seemingly dealing with the prejudice that mental illness entails. These challenges lead to immersion where some people steep themselves in the consumer-expatient-survivor movement. This immersion leads to hostility towards the 'normal' majority and rejection of psychiatric services. During the internalization phase, ideas that are learned as the result of interacting with the consumer-expatient-survivor community become part of the person's self-identity. People transition from statements about them ('The consumer community is supportive be- cause of its common bond with mental illness') to about me ('I am supportive because of my mental illness'). In the last stage of Cross' model-internalizationcommitment-the identity statements yield affective products including righteous anger and self-love.

\section{Benefits and costs to disclosing}

What are the advantages and disadvantages to coming out of the closet? Once again, we would argue that many of the consequences to coming out of the gay closet are similarly applicable to the experiences of people with mental illness. Costs and benefits are listed in Table 1. Perhaps most sobering among the risks of coming out for sexual minorities is bodily harm. The news media regularly reports on hate crimes based on sexual orientation. The case of Matthew Shepard is perhaps best known. This 21year-old gay male was beaten to death outside of Laramie, Wyoming in 1998. Unfortunately, this is not a rare occurrence. Results of one study showed $41 \%$ of a sample of lesbians and gay men reported being victims of a bias-related crime and another 9.5\% reported an attempted bias crime against them (Herek et al., 1997). Data provided by Human Rights Watch (2001) has shown that more than $80 \%$ of gay and lesbian students report incidents of name-calling and other forms of verbal harassment in a single year.

On one hand, there does not seem to be a facile comparison between these kinds of hate crimes and the experiences of people with mental illness. There is no body of evidence clearly suggesting that people with mental illness who come out are victims of crime in retaliation for their 'mentally ill' life 
Table 1: Summary of costs and benefits of coming out of the gay closet

\begin{tabular}{|l|l|}
\hline Benefits & Costs \\
\hline $\begin{array}{l}\text { Psychological well being } \\
\text { - Increased self-esteem }\end{array}$ & Physical harm \\
- Decreased distress & \\
Diminished risky behavior & Social avoidance by others \\
Facilitate interpersonal relations & Social disapproval \\
Enhance relatedness to key institutions like & Self-consciousness and self-fulfilling \\
work & prophecies \\
\hline
\end{tabular}

style. Alternatively, some advocates believe violence against people with mental illness comes in a more subtle form (Chamberlin, 1998; Fisher \& Ahern, 2000). Namely, the prescription of coercive and/or mandated treatments, such as involuntary commitments and mandated medication, has been perceived as a violent measure by some people with mental illness. Research has shown that some people with mental illness experience mandated or coercive treatment as harmful and abusive (Svensson \& Hansson, 1994).

There are other examples of less violent, but still punitive, consequences to disclosing. Many members of the general public may choose to avoid people who have come out as gay. Experiences of social disapproval may negatively impact the self-esteem of people who are out. Of even greater concern, disclosing one's sexual orientation may translate into job and housing discrimination (Ragins \& Cornwell, 2001). Although specific statistics have been difficult to gather, mounting evidence suggest that gays and lesbians suffer employment discrimination (Jennings, 1994; Olson, 1987; Weaver $v$ Nebo School District, 1998). A similar pattern has been found for people with mental illness. Individuals who are disclose their psychiatric conditions are less likely to obtain or maintain jobs because of stigma (Corrigan \& Watson, 2002).

Despite the disadvantages, benefits to disclosing a stigmatized status exist. Perhaps key among these is the removal of the stress that results from having to no longer keep a secret on such an important part of one's identity (Rosario et al., 2001). Research by Daniel Wegner and colleagues (Wegner \& Lane, 1995) has examined the deleterious effects of secrets for people with concealable stigmas. Labeling it the secrecy cycle, Wegner and colleagues found that attempts at secrecy activate a set of cognitive processes that lead to an obsessive preoccupation with the secret. Coming out negates the need for concealment and therefore helps the person avoid the secrecy cycle.

Among sexual minorities, diminished stress that results from coming out leads to better relationships with one's partner (Beals \& Peplau, 2001) and improved job satisfaction (Day \& Schoenrade, 1997, 2000). Moreover, people who come out report greater support from their families (Kadushin, 2000). Further, as a group, sexual minorities have embraced coming out as beneficial for the political and socio-economic needs of their communities. As such, advocacy groups repeat- 
edly urge individual gays and lesbians to come out at all levels.

Although the benefit for the stigmatized community seems clear, the impact on individuals within that community is less transparent. There are no algorithms that suggest how the costs and benefits of coming out will add up to affect an individual. Hence, the individual must consider these advantages and disadvantages for themselves in deciding whether or when to disclose. In the next section, several levels of disclosure, and its impact on people making the disclosure decision, are reviewed.

\section{Different levels of disclosure}

Cain (1991) interviewed 38 gay men to determine decision rules for coming out. The author asserts that people choose to disclose their gay orientation because it meets at least one of six needs. (1) Research has shown that maintaining a secret about an important aspect of one's identity is inversely related to psychological well-being (Rosario et al., 2001). Hence, disclosing the secret serves the therapeutic purpose of enhancing one's self-esteem. (2) Disclosing may enhance closeness in relationships that were distant because of the closeted secret. (3) Sometimes people disclosed as a way to resolve interpersonal problems. One specific example with relevance to mental illness was coming out to avoid constant questions about one's whereabouts when covertly involved in the gay world (or mental health community). (4) Preventive disclosures attempt to avoid worse outcomes that might occur by accidentally discovering that a person is gay. (5) Some people opt to publicly announce their sexual orientation because they believe the more people that are out, the more the homophobic majority will diminish their prejudice. (6) Finally, Cain noticed that disclosure sometimes serves a spontaneous function. Examples include onthe-spot decisions or slips of the tongue.

Cain (1991) noted that just as there are reasons why people opt to disclose, so there are functions that keep people in the closet. Called concealment, four examples are described below. (1) Often times, people believed that disclosure was neither appropriate nor relevant to the situation. For example, several people reported it would be improper to share their sexual orientation with parents who have discouraged any discussion whatsoever on sexual matters. (2) Some people opt to conceal their homosexuality out of deference to a significant other. Age was often cited as reason to defer and not tell someone (e.g., aging grandparents). (3) Some people stay in the closet because they lack the necessary emotional resources to face the challenge of disclosure. For example, they do not have the stress management skills or support to handle the disapproval and anger they may experience from others when they come out. (4) Finally, some people opt not to disclose because of concerns that people in positions of power (e.g., employer) might use the information against them.

In an ethnographic study of 146 people with mental illness, Herman (1993) identified several specific ways in which people might disclose. Based on our work with mental health advocates (Corrigan \& Lundin, 2001), we summarized her observations into five specific levels of disclosure. According to Herman (1993), at the most extreme level, people may stay in the closet through social avoidance. This means keeping away from situations where people may find 
out about one's mental illness. Instead, they only associate with other persons who have mental illness. Others may choose not to avoid social situations but instead to keep their experiences a secret. An alternative version of this is selective disclosure. Selective disclosure means there is a group of people with whom private information is disclosed and a group from whom this information is kept secret. While there may be benefits of selective disclosure such as an increase in supportive peers, there is still a secret that could represent a source of shame. People who choose indiscriminant disclosure abandon the secrecy. They choose to disregard any of the negative consequences of people finding out about their mental illness. Hence, they make no active efforts to try to conceal their mental health history and experiences. Broadcasting one's experience means educating people about mental illness. The goal here is to seek out people to share past history and current experiences with mental illness. Broadcasting has additional benefits compared to indiscriminant disclosure. Namely, it fosters their sense of power over the experience of mental illness and stigma.

\section{Ways in which coming out has been supported}

Although the decision to come out is a personal one, disclosure has been facilitated by a variety of institutions and social movements. Three of these are summarized below:

The reappropriation of stigmatizing labels Several examples to diminish the effect of a bad label are apparent from the commercial world where businesses have sought to escape prejudice by changing their names (e.g., Valujet morphed into Air Tran after a major accident). Learn- ing from these lessons, perhaps one way to deal with prejudice and discrimination is to find words that are less pejorative to describe a stigmatized group. An alternative approach is to reappropriate stigmatizing labels. In the latter instance, a stigmatized group revalues what was a negative label by referring to itself in terms of that label (Galinsky et al., 2003). Queer is an example of this phenomenon in the gay community. In 1990 four members of ACT-UP dubbed itself Queer Nation with the slogan 'We're here. We're Queer. Get used to it.' What used to be a disrespectful way of referring to sexual minorities has been embraced by the community. There is some evidence of label reappropriation in the consumer survivor community too. Perhaps the best example is MadNation. Established in 1997, MadNation now comprises more than 800 members 'working for social justice and human rights in mental health' (www.networksplus.net/fhp/madnation/announce.htm).

Galinsky et al. (2003) identified several benefits to label reappropriation. Perhaps most obvious, the public can no longer use the term against the group. Secondly, reappropriation implies that deviance or abnormality is not a bad thing. Lastly, the reappropriation of a term like queer or mad actually becomes a source of pride. In turn, this kind of pride enhances the self-esteem of individuals who willingly wear it.

Advocacy and support groups

A second social phenomenon that facilitates disclosure is the advocacy and support groups made up of people who are out. Among sexual minorities, these groups sometimes adopt a reappropriated name and become a resource in the community. Groups like these provide a range of services including support 
for those who are just coming out, recreation and shared experiences which foster a sense of community within a larger hostile culture, and advocacy/ political efforts to further promote gay pride (Kates \& Belk, 2001).

Several forces have converged over the past century to foster consumer-operated services for persons with psychiatric disabilities. Some reflect dissatisfaction with mental health services that disempower persons by providing services in restrictive settings. Others represent a natural tendency of persons to seek support from others with similar problems. Recently, a variety of consumeroperated service programs have developed including: drop in centers, housing programs, homeless services, case management, crisis response, benefit acquisition, anti-stigma services, advocacy, research, technical assistance, and employment programs (Van Tosh \& del Vecchio, 2000). Results of a qualitative evaluation of consumer operated programs showed that participants in these programs reported improvements in selfreliance and independence; coping skills and knowledge; and feelings of empowerment (Van Tosh \& del Vecchio, 2000). Future research needs to isolate the active ingredients of consumer-operated services that lead to positive change.

\section{Outing}

A third phenomenon related to disclosure is outing. In the past decade, some gay and lesbian advocates have called for outing people in the closet as a way to advance an anti-prejudice agenda. Outing means publicizing the fact that a specific person is gay or lesbian when that person has actively tried to stay in the closet. Outing generates strong ethical debate (Chekola, 1994; Mayo \& Gunderson, 1994; McCarthy, 1994) and may vary from what is frequently considered the most justified position (e.g., publicly outing a conservative politician who takes an anti-gay stand on important public issues) to the least (e.g., outing a private citizen who keep all facets of his or her life private). In a parallel fashion, people active in the mental illness community might opt to out individuals in the closet about their psychiatric problems. There have been examples of the psychiatric problems of famous people being disclosed for political agenda. Perhaps best known of these was Thomas Eagleton's experiences with depression which were leaked to the press. Senator Eagleton, a democrat from Missouri, was George McGovern's running mate in the 1972 general presidential election. In this instance, however, outing Eagleton was not to serve mental health pride but to increase prejudice. Similarly, there is not yet any empirical evidence that outing has somehow diminished either prejudicial attitudes or discriminatory behaviors toward gays. This needs to be the focus of future research.

\section{Conclusion}

For the gay and lesbian community coming out has significant advantages at the individual and community level. We argued in this paper that the experiences of stigma are similar for gays/lesbians and people with mental illness. Hence, what the gay community has learned about coming out may inform a similar movement in the community of people who identify themselves as mentally ill. In the process, the research that has examined some of the questions related to identity development and disclosure in the gay community may inform similar experiences in people with mental illness. This 
review has provided a preliminary understanding of the coming out process. It has also illustrated some methods for further examining research questions in this area. In particular, research needs to continue to examine the ways in which the various ways to come out impact the individual as well as the community as a whole.

\section{Acknowledgements}

Many thanks to Galen Bodenhausen and Marie Ciavarella for helpful comments on an earlier draft of this paper.

\section{References}

Amador, X.F. \& Kronengold, H. (1998). The description and meaning of insight in psychosis. In X.F. Amador \& A.S. David (eds.), Insight and psychosis. New York: Oxford University Press.

American Psychiatric Association (1952). Diagnostic and statistical manual of mental disorders (1st ed.). Washington: Author.

American Psychiatric Association (1968). Diagnostic and statistical manual of mental disorders (2nd ed.). Washington: Author.

American Psychiatric Association (1980). Diagnostic and statistical manual of mental disorders (3rd ed.). Washington: Author.

American Psychiatric Association (1987). Diagnostic and statistical manual of mental disorders (3rd ed., revised). Washington: Author.

American Psychiatric Association (1994). Diagnostic and statistical manual of mental disorders (4th ed.). Washington: Author.

American Psychiatric Association (2000). Diagnostic and statistical manual of mental disorders (4th ed., revised). Washington: Author.

Beals, K.P. \& Peplau, L.A. (2001). Social involvement, disclosure of sexual orientation, and the quality of lesbian relationships. Psychology of Women Quarterly, 25, 10-19.

Besner, H.F. \& Spungin, C.I. (1995). Gay and lesbian students: Understanding their needs. Philadelphia: Taylor \& Francis.

Brady, S. \& Busse, W.J. (1994). The Gay Identity Questionnaire: A brief measure of homosexual identity formation. Journal of Homosexuality, $26,1-22$.
Brookey, R.A. (2000). Saints or sinners: Sociobiological theories of male homosexuality. International Journal of Sexuality \& Gender Studies, 5, 37-58.

Cain, R. (1991). Stigma management and gay identity development. Social Work, 36, 67-73.

Cass, V.C. (1979). Homosexual identity formation: A theoretical model. Journal of Homosexuality, 4, 219-235.

Cass, V.C. (1984). Homosexual identity formation: Testing a theoretical model. Journal of Homosexuality, 20, 143-167.

Chamberlin, J. (1998). Citizenship rights and psychiatric disability. Psychiatric Rehabilitation Journal, 21, 405-408.

Chekola, M. (1994). Outing, truth-telling, and the shame of the closet. Journal of Homosexuality, 27, 67-90.

Corrigan, P.W. (2000). Mental health stigma as social attribution: Implications for research methods and attitude change. Clinical Psychology-Science \& Practice, 7, 48-67.

Corrigan, P.W. \& Lundin, R.K. (2001). Don't Call Me Nuts! Coping with the Stigma of Mental Illness. Tinley Park, IL: Recovery Press.

Corrigan, P.W. \& Watson, A.C. (2002). The paradox of self-stigma and mental illness. Clinical Psychology-Science \& Practice, 9, $35-53$.

Corrigan, P.W., River, L., Lundin, R.K., Penn, D.L., Uphoff-Wasowski, K., Campion, J., Mathisen, J., Gagnon, C., Bergman, M., Goldstein, H. \& Kubiak, M.A. (2001). Three strategies for changing attributions about severe mental illness. Schizophrenia Bulletin, 27, $187-195$.

Corrigan, P.W., Rowan, D., Green, A., Lundin, R., River, P., Uphoff-Wasowski, K., White, K. \& Kubiac, M.A. (2003). Challenging two mental illness stigmas: Personal responsibility and dangerousness. Schizophrenia Bulletin, 28, $293-310$.

Cover, R. (2000). First contact: Queer theory, sexual identity and "mainstream" film. International Journal of Sexuality \& Gender Studies, 5, $71-89$.

Cross, W.E. (1971). Toward a psychology of Black liberation: The Negro-to-Black conversion experience. Black World, 20, 13-27.

Crossley, N. (1998). R.D. Laing and the British anti-psychiatry movement: A socio-historic analysis. Social Science \& Medicine, 47, $877-$ 889. 
Davies, D., \& Neal, C. (eds.). (2000). Therapeutic perspectives on working with lesbian, gay and bisexual clients. Philadelphia: Open University Press.

Day, N.E. \& Schoenrade, P. (1997). Staying in the closet versus coming out: Relationships between communication about sexual orientation and work attitudes. Personnel Psychology, $50,147-163$.

Day, N.E. \& Schoenrade, P. (2000). The relationship among reported disclosure of sexual orientation, anti-discrimination policies, top management support and work attitudes of gay and lesbian employees. Personnel Review, 29, 346-363.

Drake, R.E., Goldman, H.E., Leff, H., Lehman, A.F., Dixon, L., Mueser, K.T. \& Torrey, W.C. (2001). Implementing evidence-based practices in routine mental health service settings. Psychiatric Services, 52, 179-182.

Duberman, M. (1993). Stonewall. New York: Dutton.

Fisher, B. \& Akman, J.S. (2002). Normal development in sexual minority youth. In B. E. Jones \& M. J. Hill (eds.), Mental health issues in lesbian, gay, bisexual, and transgender communities Review of psychiatry. Washington, DC: American Psychiatric Publishing, Inc.

Fisher, D.B. (1994). Health care reform based on an empowerment model of recovery by people with psychiatric disabilities. Hospital \& Community Psychiatry, 45, 913-915.

Fisher, D.B. \& Ahern, L. (2000). Personal Assistance in Community Existence (PACE): An alternative to PACT. Ethical Human Sciences \& Services, 2, 87-92.

Foucault, M. (Ed.). (1980). Herculine Barbin: Being the Recently Discovered Memoirs of a Nineteeth-Century French Hermaphrodite. New York: Pantheon.

Frese, F.J. \& Davis, W.W. (1997). The consumersurvivor movement, recovery, and consumer professionals. Professional Psychology-Research \& Practice, 28, 243-245.

Galinsky, A.D., Hugenberg, K., Groom, C. \& Bodenhausen, G. (2003). The reappropriation of stigmatizing labels: Implications for social identity. In M. A. Neale, E. A. Mannix, \& J. Polzer (Eds.), Research on managing groups and teams. Greenwich, CT: Elsevier Science Press.

Goffman, E. (1963). Stigma: Notes on the management of spoiled identity. Englewood Cliffs, NJ: Prentice-Hall.
Hall, W.S., Freedle R. \& Cross, W.E. (1972). Stages in the development of a black identity. Act Research Reports No, 50(21).

Herek, G.M. (1986). On heterosexual masculinity: Some psychical consequences of the social construction of gender and sexuality. American Behavioral Scientist, 29, 563-577.

Herek, G.M. (1996). Heterosexism and homophobia. In R.P. Cabaj \& T.S. Stein (eds.), Textbook of homosexuality and mental health. Washington: American Psychiatric Press.

Herek, G.M. \& Capitanio, J.P. (1996). 'Some of my best friends': Intergroup contact, concealable stigma, and heterosexuals' attitudes toward gay men and lesbians. Personality \& Social Psychology Bulletin, 22, 412-424.

Herek, G.M., Gillis, J., Cogan, J.C. \& Glunt, E.K. (1997). Hate crime victimization among lesbian, gay, and bisexual adults. Journal of Interpersonal Violence, 12, 195-215.

Herman, N.J. (1993). Return to sender: Reintegrative stigma-management strategies of expsychiatric patients. Journal of Contemporary Ethnography, 22, 295-330.

Holmes, E., Corrigan, P.W., Williams, P., Canar, J. \& Kubiak, M.A. (1999). Changing attitudes about schizophrenia. Schizophrenia Bulletin, $25,447-456$.

Human Rights Watch. (2001). World Report. New York: Author.

Jennings, K. (1994). Becoming Visible. Los Angeles: Alyson Publications.

Johnson, C.C. \& Johnson, K.A. (2000). High-risk behavior among gay adolescents: Implications for treatment and support. Adolescence, 35, $619-637$.

Jones, J.M., Lynch, P.D., Tenglund, A.A. \& Gaertner, S.L. (2000). Toward a diversity hypothesis: Multidimensional effects of intergroup contact. Applied \& Preventive Psychology, 9, 53-62.

Kadushin, G. (2000). Family secrets: Disclosure of HIV status among gay men with HIV/AIDS to the family of origin. Social Work in Health Care, 30, 1- 17.

Kates, S.M. \& Belk, R.W. (2001). The meanings of Lesbian and Gay Pride Day: Resistance through consumption and resistance to consumption. Journal of Contemporary Ethnography, 30, 392-429.

Keane, C. (1991). Socioenvironmental determinants of community formation. Environment \& Behavior, 23, 27-46. 
Kinzie, J. (2000). The historical relationship between psychiatry and the major religions. In J.K. Boehnlein (ed.), Psychiatry and religion: The convergence of mind and spirit issues in psychiatry. Washington: American Psychiatric Publishing.

Link, B.G. \& Cullen, F.T. (1986). Contact with the mentally ill and perceptions of how dangerous they are. Journal of Health \& Social Behavior, 27, 289-302.

Link, B.G. \& Phelan, J.C. (2001). Conceptualizing stigma. Annual Review of Sociology, 27, 363385.

Mayo, D.J. \& Gunderson, M. (1994). Privacy and the ethics of outing. Journal of Homosexuality, 27, 47-65.

McCarn, S.R. \& Fassinger, R.E. (1996). Revisioning sexual minority identity formation: A new model of lesbian identity and its implications. Counseling Psychologist, 24, 508-534.

McCarthy, J. (1994). The closet and the ethics of outing. Journal of Homosexuality, 27, 27-45.

McEvoy, J.P. (1998). The relationship between insight in psychosis and compliance with medications, In X.F. Amador \& A.S. David (eds.), Insight and psychosis. New York: Oxford University Press.

Mio, J.S. \& Iwamasa, G. (1993). To do, or not to do: That is the question for White crosscultural researchers. Counseling Psychologist, 21, 197-212.

Morrison, J.K. (1980). The public's current beliefs about mental illness: Serious obstacle to effective community psychology. American Journal of Community Psychology, 8, $697-$ 707.

Mosher, L.R. \& Burti, L. (1992). Relationships in rehabilitation: When technology fails. Psychosocial Rehabilitation Journal, 15, 11-17.

Narrow, W.E., Rae, D.S., Robins, L.N. \& Regier, D.A. (2002). Revised prevalence based estimates of mental disorders in the United States: using a clinical signficance criterion to reconcile 2 surveys' estimates. Archives of General Psychiatry, 59, 115-123.

Olson, M.R. (1987). A study of gay and lesbian teachers. Journal of Homosexuality, 13, 73-81.

Parham, T.A. (1989). Cycles of psychological Nigrescence. Counseling Psychologist, 17, $187-226$.

Penn, D.L., Guynan, K., Daily, T., Spaulding, W.D., Garbin, C.P. \& Sullivan, M. (1994). Dispelling the stigma of schizophrenia: What sort of information is best? Schizophrenia Bulletin, 20, 567-578.
Penn, D.L., Kommana, S., Mansfield, M. \& Link, B.G. (1999). Dispelling the stigma of schizophrenia: II. The impact of information on dangerousness. Schizophrenia Bulletin, 25, $437-446$.

Ponterotto, J.G. \& Sabnani, H.B. (1989). 'Classics' in multicultural counseling: A systematic five-year content analysis. Journal of Multicultural Counseling \& Development, 17, 23-37.

Ragins, B.R. \& Cornwell, J.M. (2001). Pink triangles: Antecedents and consequences of perceived workplace discrimination against gay and lesbian employees. Journal of Applied Psychology, 86, 1244-1261.

Ridley, C.R., Mendoza, D.W. \& Kanitz, B.E. (1994). Multicultural training: Reexamination, operationalization, and integration. Counseling Psychologist, 22, 227-289.

Rosario, M., Hunter, J., Maguen, S., Gwadz, M. \& Smith, R. (2001). The coming-out process and its adaptational and health-related associations among gay, lesbian, and bisexual youths: Stipulation and exploration of a model. American Journal of Community Psychology, 29, 113-160.

Savin-Williams, R.C. (2001). Mom, dad, I'm Gay. How families negotiate coming out. Washington: American Psychological Association.

Sophie, J. (1985). A critical examination of stage theories of lesbian identity development. Journal of Homosexuality, 12, 39-51.

Svensson, B. \& Hansson, L. (1994). Patient satisfaction with inpatient psychiatric care: The influence of personality traits, diagnosis and perceived coercion. Acta Psychiatrica Scandinavica, 90, 379-384.

Trainor, J., Shepherd, M., Boydell, K.M., Leff, A. \& Crawford, E. (1997). Beyond the service paradigm: The impact and implications of consumer/survivor initiatives. Psychiatric Rehabilitation Journal, 21, 132-140.

Van Tosh, L. \& del Vecchio, P. (2000). Consumer/ survivor-operated self-help programs: A technical report. Rockville, MD: Department of Health and Human Services.

Vincke, J., De Rycke, L., \& Bolton, R. (1999). Gay identity and the experience of gay social stress. Journal of Applied Social Psychology, 29, 1316-1331.

Weaver v. Nebo School District., 29 F. Supp. 2d 1279 (C. D. Utah 1998).

Wegner, D.M. \& Lane, J.D. (1995). From secret to psychopathology. In J.W. Pennebaker (ed.), Emotion, disclosure, \& health. Washington: American Psychological Association. 
Weiser, M., Reichenberg, A., Rabinowitz, J., Kaplan, Z., Mark, M., Bodner, E., Nahon, D. \& Davidson, M. (2001). Association between nonpsychotic psychiatric diagnoses in adolescent males and subsequent onset of schizophrenia. Archives of General Psychiatry, $58,959-964$.
Zachary, A. (2001). Uneasy triangles: A brief overview of the history of homosexuality. British Journal of Psychotherapy, 17, 489-492. 